\title{
CONTINUOUS-FLOW EXTRACTION OF BIOCOMPOUNDS IN FIXED BED: INFLUENCE OF SWAPPING FROM DIRICHLET TO DANCKWERTS CONDITION AT INLET IN PHENOMENOLOGICAL MODELS
}

\author{
EXTRAÇÃO DE BIOCOMPOSTOS EM FLUXO CONTÍNUO EM LEITO FIXO: \\ INFLUÊNCIA DA TROCA DE CONDIÇÃO DE DIRICHLET PARA DANCKWERTS NA \\ ENTRADA EM MODELOS FENOMENOLÓGICOS \& \\ EXTRACCIÓN DE BIOCOMPUESTOS A FLUJO CONTINUO EN LECHO FIJO: \\ INFLUENCIA DEL CAMBIO DE CONDICIÓN DE DIRICHLET A DANCKWERTS A LA \\ ENTRADA EN MODELOS FENOMENOLÓGICOS \&
}

Recebido em: 08/05/2021 - Aprovado em: 19/11/2021 - Publicado em: 29/11/2021

do http://dx.doi.org/10.18011/bioeng2021v15n4p538-560

Naila Albertina de Oliveira ${ }^{1}$ (nailaa.oliveira@gmail.com) José Antonio Rabi² (jrabi@usp.br)

\footnotetext{
${ }^{1}$ UniMAX - Centro Universitário Max Planck. Indaiatuba, SP, Brasil.

2 USP - Universidade de São Paulo. Pirassununga, SP, Brasil.
}

\begin{abstract}
Phenomenological models have increasingly become vital to bioprocess engineering. In continuous-flow biocompounds extraction models, diffusion requires an extra boundary condition at exit (usually null Neumann condition) while either Dirichlet or Danckwerts condition can be imposed at inlet. By taking an extant case study and with the help of an in-house lattice-Boltzmann simulator, this work numerically examines prospective effects of interchanging aforesaid inlet conditions. Trial simulations were performed for scenarios ranging from convection-dominant to diffusion-dominant. Extraction yields numerically simulated under each inlet condition were compared with experimental data. Expected shape of extraction yield curves was simulated whenever process parameters were properly provided and differences due to switching inlet conditions became evident only in diffusion-dominant extraction scenarios. At diffusivities of order $10^{-6} \mathrm{~m}^{2} \mathrm{~s}^{-1}$, numerical results suggest that Danckwerts boundary condition should be preferred at bed inlet.
\end{abstract}

Keywords: Bioproducts. Bioprocesses. Mathematical modeling. Numerical simulation. Lattice Boltzmann method. 


\section{INTRODUCTION}

\subsection{BIOCOMPOUNDS EXTRACTION: EXTENDING PHYSICS-BASED MODELS}

Computational modeling (sometimes referred to as virtualization) has progressively become strategic for research, development and innovation (RD\&I) in food engineering (SAM SAGUY, 2016) as well as in biosystems engineering. Earlier works using numerical simulation have been reviewed for (but not limited to) emissions from livestock buildings (CALVET et al., 2013), crops with agricultural screen (TANNY, 2013), agricultural granular materials (HORABIK; MOLENDA, 2016), and either carbon dioxide control (LI et al., 2018) or ventilation-cooling within greenhouses (GHOULEM et al., 2019).

As far as biocompounds extraction is concerned, virtualization has long supported design, scale-up and optimization from lab to industrial scale (DIAZ; BRIGNOLE, 2009). Continuous-flow extraction of natural compounds relies on key process parameters (DE OLIVEIRA et al., 2018) and numerical simulation can rapidly examine 'what-if' scenarios towards optimal extraction (BERTOLDI et al., 2021). Recent trends in numerical simulation of biosystems have pointed to combining heuristic techniques (e.g. machine learning) with phenomenological (e.g. multiphysics) models (ALBER et al., 2019).

While mathematical models have long been proposed for biocompounds extraction (SOVOVÁ, 1994; REVERCHON, 1996), they have been constantly evaluated (RAl et al., 2014). As model extensions towards comprehensiveness are vital for process engineering, oversimplifications should be circumvented (DE SOUZA-SANTOS, 2010). Physics-based models should rely on realistic governing differential equations together with suitable initial and/or boundary conditions.

\subsection{BIOCOMPOUNDS EXTRACTION: EXTENDING NUMERICAL SIMULATION}

Bioprocesses virtualization has benefited from novel computational methods such as lattice Boltzmann method (LBM) (VAN DER SMAN, 2007). Launched in MCNAMARA; ZANETTI (1988), LBM can numerically simulate either fluid flow or transport phenomena without directly solving Navier-Stokes equations (SUCCI, 2001), thus saving several code lines. As LBM renders relatively simpler codes (MOHAMAD, 2011), it comes forward as an attractive virtualization route to implement in-house simulators. 
As part of ongoing research, in-house LBM simulators have been developed and extended towards biosystems and bioprocesses (OKIYAMA; RABI, 2013; DURÁN et al., 2015; OKIYAMA et al., 2015; RABI; KAMIMURA, 2016; ROSA et al., 2016; FORTUNATO et al., 2018; RABI et al., 2020; BERTOLDI et al., 2021). Friendly named as IRENE (In-house Reification Environment for Numerical Experimentation), such LBM simulators have thus far relied on time-dependent one-dimensional models. Though limited to dynamic 1-D problems, physics-based models in IRENE consider not only convection but also diffusion (expressed via elliptic differential equations). Therefore, from phenomenological viewpoint, IRENE can actually deal with relatively more comprehensive models.

In order to virtualize biosystems and bioprocesses, governing differential equations in IRENE invoke several process parameters, which are input values to be user-supplied. As IRENE has computationally relied on input parameters taken from the literature (but not necessarily fine-tuned through similar models), values best-fitted against relatively simpler differential equations (e.g. parabolic rather than elliptic) or dissimilar boundary conditions (e.g. Dirichlet instead of Danckwerts) could be conceivably misleading.

\subsection{BIOCOMPOUNDS EXTRACTION: NUMERICAL EFFECTS OF INLET CONDITIONS}

In order to virtualize bioprocesses (e.g. natural compounds extraction), IRENE has originally imposed Dirichlet inlet condition, although Danckwerts inlet condition could be alternatively imposed. Inspired by a previous LBM study (RABI; KAMIMURA, 2016), the present work aimed at examining how those two inlet conditions may influence continuousflow extraction in fixed-bed equipment as numerically simulated via IRENE.

Since its early versions IRENE has considered chemical species (mass) diffusion in distinct phases, thus rendering an elliptic governing differential equation. Mathematically, a $2^{\text {nd }}$-order spatial derivative arises to model diffusion so that an extra boundary condition becomes required, usually at exit. From computational viewpoint, 'marching methods' (e.g. Runge-Kutta method) are no longer allowable and they should be replaced by 'iterative sweeping methods' (e.g. spatial discretization methods), which is the case of LBM.

Accordingly, the present work aimed at examining numerical effects in IRENE due to adopting input parameters fine-tuned through extraction models neglecting diffusion. In addition, LBM simulations explored the prospective influence on extraction virtualization as 
(i) continuous-flow extraction ranged from convection-dominant to diffusion-dominant and

(ii) Dirichlet and Danckwerts boundary conditions were interchanged at bed inlet.

As means to perceive those numerical effects, an extant work on continuous-flow extraction of essential oil from Baccharis trimera (gorse) in fixed-bed equipment (VARGAS et al., 2006) was properly taken as case study. While VARGAS et al. (2006) is relatively dated, it is a suitable mathematical choice to check numerical effects in IRENE because (i) their governing differential equations disregard mass diffusion in fluid phase and (ii) only Dirichlet boundary condition is imposed at bed inlet.

\section{THEORY}

\subsection{CONTINUOUS-FLOW EXTRACTION IN FIXED BED: PHYSICS-BASED MODELING}

In line with VARGAS et al. (2006), the present work follows a dynamic 1-D physicsbased model in which species (namely, essential oil) concentrations are functions of time $t$ and axial position $x$, respectively indicated as $c_{\mathrm{f}}=c_{\mathrm{f}}(t, x)$ and $c_{\mathrm{s}}=c_{\mathrm{s}}(t, x)$ in flowing solvent (fluid phase) and gorse particles (solid phase). Extractor is modeled as stratified cylindrical fixed bed with diameter $d$ and uniform porosity $\varepsilon$. Stratification axis $x$ is flow-oriented so that bed inlet and exit are respectively at $x=0$ and $x=L$ (= bed length). Volumetric flow rate $\dot{V}$ of solvent is assumed to remain constant so that interstitial velocity $v$ of flowing solvent results constant and uniform, namely:

$$
v=\frac{4 \dot{V}}{\varepsilon \pi d^{2}}
$$

Let $\dot{r}$ be the local instantaneous rate at which essential oil is extracted from gorse particles to the flowing solvent. In VARGAS et al. (2006), such transfer rate is modeled as:

$$
\dot{r}=\frac{1}{t_{\text {int }}}\left(c_{\mathrm{s}}-\frac{c_{\mathrm{f}}}{k_{\mathrm{p}}}\right) \quad, \quad t_{\text {int }}=\frac{l_{\mathrm{p}}^{2} \mu}{D_{\text {int }}}
$$

where $k_{\mathrm{p}}$ and $t_{\text {int }}$ are respectively known as partition coefficient and intra-particle diffusion time. The latter is assessed from particle characteristic length $l_{\mathrm{p}}$, particle shape coefficient $\mu$, and intra-particle diffusivity $D_{\text {int }}$ (of essential oil), as indicated in Eq. (2).

As $\dot{r}$ is the instantaneous rate at which gorse particles lose essential oil, it behaves as a sink term with respect to the solid-phase concentration $c_{\mathrm{s}}$ and the following governing differential equation then holds: 


$$
\frac{\partial c_{\mathrm{s}}}{\partial t}=-\dot{r}
$$

On the other hand, this very same rate $\dot{r}$ behaves as a source term with regard to the fluidphase concentration $c_{\mathrm{f}}$. By invoking species transport through convection as well as diffusion in the fluid phase, the following partial differential equation (PDE) applies:

$$
\varepsilon \frac{\partial c_{\mathrm{f}}}{\partial t}+\varepsilon v \frac{\partial c_{\mathrm{f}}}{\partial x}=\varepsilon D_{\mathrm{f}} \frac{\partial^{2} c_{\mathrm{f}}}{\partial x^{2}}+(1-\varepsilon) \dot{r} \quad \stackrel{\div \varepsilon}{\longrightarrow} \quad \frac{\partial c_{\mathrm{f}}}{\partial t}+v \frac{\partial c_{\mathrm{f}}}{\partial x}=D_{\mathrm{f}} \frac{\partial^{2} c_{\mathrm{f}}}{\partial x^{2}}+\frac{1-\varepsilon}{\varepsilon} \dot{r}
$$

where $D_{\mathrm{f}}$ is species (i.e. essential oil) diffusivity in the fluid phase (i.e. flowing solvent).

VARGAS et al. (2006) disregarded diffusive transport in their governing PDE for essential oil concentration in fluid phase, which is equivalent to impose $D_{\mathrm{f}}=0$ in Eq. (4). It is precisely this modeling constraint that makes VARGAS et al. (2006) an interesting work for comparison purposes as diffusion has been modeled in IRENE since its early versions (OKIYAMA; RABI, 2013) owing to its relevance in long (i.e. industrial-scale) extraction equipment (GASPAR et al., 2003). For that reason, $D_{\mathrm{f}}$ arises as additional input parameter in continuous-flow extraction models, besides those in Table 1 and Table 2.

Table 1 - Extraction of essential oil from gorse: temperature-independent input parameters.

\begin{tabular}{lll}
\hline \multirow{2}{*}{ Fixed bed parameters } & Length & $L=0.045 \mathrm{~m}$ \\
& Diameter & $d=0.011 \mathrm{~m}$ \\
& Porosity & $\varepsilon=0.669$ (dimensionless) \\
\hline \multirow{3}{*}{ Solid phase parameters } & Maximum extraction capacity & $c_{\max }=27.0 \mathrm{~kg} \mathrm{~m}^{-3}$ \\
& Particle characteristic length & $l_{\mathrm{p}}=0.0005 \mathrm{~m}$ \\
& Particle shape coefficient & $\mu=1 / 3$ (dimensionless) \\
& Total sample mass in bed & $m_{\text {total }}=0.0015 \mathrm{~kg}$ \\
\hline \multirow{2}{*}{ Fluid phase parameter } & Volumetric flow rate & $\dot{V}=\frac{1}{3} \times 10^{-7} \mathrm{~m}^{3} \mathrm{~s}^{-1}$ \\
\hline
\end{tabular}

Source: VARGAS et al., 2006.

Table 2 - Extraction of essential oil from gorse: temperature-dependent input parameters.

\begin{tabular}{lcccc}
\hline Extraction parameter (symbol, units) at: & $\boldsymbol{T}=\mathbf{4 0}^{\circ} \mathbf{C}$ & $\boldsymbol{T = 5 0 ^ { \circ } \mathbf { C }}$ & $\boldsymbol{T = 6 0 ^ { \circ } \mathbf { C }}$ & $\boldsymbol{T = 7 0 ^ { \circ } \mathbf { C }}$ \\
\hline Partition coefficient $\left(k_{\mathrm{p}}\right.$, dimensionless) & 0.8133 & 0.6944 & 0.1041 & 0.0667 \\
\hline Intra-particle oil diffusivity $\left(D_{\text {int }}, \mathrm{m}^{2} \mathrm{~s}^{-1}\right)$ & $3.03 \times 10^{-11}$ & $3.66 \times 10^{-11}$ & $1.97 \times 10^{-10}$ & $2.73 \times 10^{-10}$ \\
\hline
\end{tabular}

Source: VARGAS et al., 2006.

At process start-up, maximum extraction capacity $c_{\max }$ is uniformly assumed within gorse particles whereas null concentration is assigned throughout the interstitial solvent. Mathematically imposed for $0 \leq x \leq L$ at $t=0$, those two initial conditions in solid and fluid 
phases are respectively expressed as:

$$
c_{\mathrm{s}}(0, x)=c_{\max } \neq 0 \quad, \quad c_{\mathrm{f}}(0, x)=c_{0}=0
$$

As Eq. (3) explicitly lacks partial derivatives with respect to coordinate $x$, it needs no boundary conditions. In opposition, two boundary conditions must be invoked to solve Eq. (4). Null Neumann condition (i.e. developed concentration profile) can be imposed at bed exit $(x=L)$ throughout the extraction process (for $t>0$ ), namely:

$$
\left.\frac{\partial c_{\mathrm{f}}}{\partial x}\right|_{x=L}=0
$$

Let $c_{\text {in }}$ be oil concentration in incoming solvent, which is assumed to be clean (i.e. $c_{\text {in }}=0$ ). At bed inlet $(x=0)$, one can impose Dirichlet condition for $t>0$ as in VARGAS et al. (2006):

$$
c_{\mathrm{f}}(t, 0)=c_{\text {in }}
$$

Alternatively (and as recently extended in IRENE), one may impose Danckwerts boundary condition (DANCKWERTS, 1953) at bed inlet $(x=0)$ for $t>0$, namely:

$$
v c_{\text {in }}=v c_{\mathrm{f}}(t, 0)-\left.D_{\mathrm{f}} \frac{\partial c_{\mathrm{f}}}{\partial x}\right|_{x=0}
$$

which simplifies to Dirichlet boundary condition, Eq. (7), for $D_{\mathrm{f}}=0$ (i.e. no diffusion).

\subsection{RATIONALE OF LATTICE BOLTZMANN METHOD (LBM)}

LBM treats any macroscopic (i.e. observable) medium, whether solid or fluid, as allegedly comprised by sets of fictitious particles populating a discrete space, namely an equally fictitious lattice structure. During discrete advancing time steps, particle ensembles concurrently stream via lattice links and mutually collide when they simultaneously arrive at lattice sites. Due to those collisions, particle velocities become rearranged for further and iterative streaming-collision (mesoscopic) dynamics.

LBM mathematically relies on particle distribution functions $f=f(t, \vec{r}, \vec{u})$ providing the "density" of particle ensembles (i.e. number of fictitious particles per unit volume) at time $t$ and about position $\vec{r}$, with streaming velocities between $\vec{u}$ and $\vec{u}+\mathrm{d} \vec{u}$. Macroscopic quantities (e.g. species concentration) are retrieved from appropriate moments of particle distribution functions $f$ (SUCCI, 2001; MOHAMAD, 2011).

Particle distribution function $f$ is ruled by Boltzmann transport equation. In LBM, this governing equation is numerically solved in view of the fictitious lattice assigned to the true medium, when it becomes referred to as lattice Boltzmann equation (LBE). LBM lattices are 
identified as $D n Q m$, where $n$ and $m$ respectively refer to problem dimension (e.g. $n=1$ for 1 D problems) and streaming model ( $m=$ number of possible streaming velocities of fictitious particles, as dictated by the fictitious lattice structure).

Space-time discretization of LBE yields algebraic equations to be solved for functions $f_{k}$ related to particles streaming via link $k$ in the fictitious lattice. For example, the repetitive linear structure of D1Q2 lattice (for 1-D problems) entails a central site linked to one site in forward streaming $(k=1)$ and one site in backward streaming $(k=2)$. LBE must then be numerically solved for functions $f_{1}$ (forward particle ensembles) and $f_{2}$ (backward particle ensembles). In D1Q2 lattice, consecutive sites are uniformly separated by $\Delta x_{k}$, where $\Delta x_{1}=$ $+\Delta x$ is for forward streaming whereas $\Delta x_{2}=-\Delta x$ refers to backward streaming.

\section{NUMERICAL METHOD}

IRENE has been continuously developed and extended as part of ongoing research on computational modeling to support agroindustrial engineering. From the mathematical viewpoint, IRENE relies on dynamic 1-D models; from the phenomenological viewpoint, it deals with transport phenomena in media partially or fully filled up with porous material. As output, IRENE can provide any chemical species concentration as a function of time and axial (1-D) position within the solution domain.

Computationally speaking, IRENE entails a series of in-house (i.e. tailor-made) codes implemented in Fortran; in other words, IRENE is not off-the-shelf (i.e. commercial) software. Either expressed in primitive or dimensionless variables, governing differential equations (whether or not coupled to each other) are numerically solved through LBM by following code lines and computational routines similar to those in MOHAMAD (2011).

\subsection{LBM SIMULATION OF DYNAMIC 1-D CONTINUOUS-FLOW EXTRACTION}

As this work relies on a dynamic 1-D model, LBM simulations used D1Q2 lattice $(k=$ 1, 2). Particle distribution functions $s_{k}=s_{k}(t, x)$ and $f_{k}=f_{k}(t, x)$ were assigned to essential oil concentrations in solid and fluid phases, respectively. Hence, at any time $t$ and position $x$ in the fixed-bed extractor, those oil concentrations can be retrieved simply as:

$$
c_{\mathrm{s}}(t, x)=\sum_{k} s_{k}(t, x)=s_{1}(t, x)+s_{2}(t, x) \quad, \quad c_{\mathrm{f}}(t, x)=\sum_{k} f_{k}(t, x)=f_{1}(t, x)+f_{2}(t, x)
$$




\subsection{LBM COLLISION AND STREAMING STEPS}

In LBM, collision is the iterative step that updates all particle distribution functions $\left(s_{k}\right.$ and $f_{k}$ in this work) from instant $t$ to $t+\Delta t$ at every lattice site in the solution domain, where $\Delta t$ is the advancing time step. As either source or sink terms can be included at this LBM step, Eqs. (3) and (4) dictated the following implementation of collision step in IRENE:

$$
\begin{array}{lll}
s_{k}(t+\Delta t, x)=\left[1-\omega_{\mathrm{s}}\right] s_{k}(t, x)+\omega_{\mathrm{s}} s_{k}^{\mathrm{eq}}(t, x)+w_{k} \dot{S}_{\mathrm{s}} \Delta t & , & \dot{S}_{\mathrm{s}}=-\dot{r} \\
f_{k}(t+\Delta t, x)=\left[1-\omega_{\mathrm{f}}\right] f_{k}(t, x)+\omega_{\mathrm{f}} f_{k}^{\mathrm{eq}}(t, x)+w_{k} \dot{S}_{\mathrm{f}} \Delta t & , & \dot{S}_{\mathrm{f}}=\dot{r}(1-\varepsilon) / \varepsilon
\end{array}
$$

where $\omega_{\mathrm{s}}$ and $\omega_{\mathrm{f}}$ are referred to as relaxation factors, $s_{k}^{\mathrm{eq}}(x, t)$ and $f_{k}^{\mathrm{eq}}(x, t)$ are particle distribution functions at equilibrium, and $w_{k}$ are lattice-dependent weighting factors. Next, those LBM parameters are addressed and presented in line with MOHAMAD (2011).

In view of the dynamic 1-D model adopted in this work, relaxation factors become:

$$
\begin{aligned}
& \frac{1}{\omega_{\mathrm{s}}}=\frac{1}{2}+\frac{D_{\mathrm{s}} \Delta t}{(\Delta x)^{2}} \stackrel{D_{\mathrm{s}} \rightarrow 0}{\longrightarrow} \omega_{\mathrm{s}}=2 \\
& \frac{1}{\omega_{\mathrm{f}}}=\frac{1}{2}+\frac{D_{\mathrm{f}} \Delta t}{(\Delta x)^{2}} \stackrel{\mathrm{Ma}, \mathrm{Pe}_{\mathrm{m}}}{\longrightarrow} \omega_{\mathrm{f}}=\left(\frac{1}{2}+\frac{\mathrm{Ma}}{\mathrm{Pe}_{\mathrm{m}}}\right)^{-1}
\end{aligned}
$$

where $\mathrm{Ma}=v \cdot \Delta t / \Delta x$ and $\mathrm{Pe}_{\mathrm{m}}=v \cdot \Delta x / D_{\mathrm{f}}$ are respectively Mach number and mass-transfer Péclet number, both lattice-based (i.e. assessed from LBM parameters $\Delta t$ and $\Delta x$ ).

By recalling that solid phase remains stationary while convective-diffusive transport is contemplated in fluid phase, equilibrium distribution functions were implemented as:

$$
s_{k}^{\mathrm{eq}}(t, x)=w_{k} c_{\mathrm{s}}(t, x) \quad, \quad f_{k}^{\mathrm{eq}}(t, x)=w_{k} c_{\mathrm{f}}(t, x)(1 \pm \mathrm{Ma})
$$

When evaluating function $f_{k}^{\text {eq }}$, the sign before Ma is positive for forward streaming $(k=1)$ or negative for backward streaming $(k=2)$. Weighting factors $w_{k}$ in Eq. (12) are the same as in Eq. (10), namely $w_{1}=w_{2}=1 / 2$ for D1Q2 lattice, as adopted in the present work.

During LBM streaming step, collision outcomes are transported to adjacent lattice sites. As Eq. (3) has no partial derivatives with respect to coordinate $x$, it was possible to suppress the streaming step for solid-phase particle distribution functions $s_{k}$ with no loss of functionality (OKIYAMA; RABI, 2013). For that reason, streaming step was implemented for fluid-phase particle distribution functions only, namely:

$$
f_{k}\left(t+\Delta t, x+\Delta x_{k}\right)=f_{k}(t+\Delta t, x)
$$




\subsection{INITIAL AND BOUNDARY CONDITIONS}

Initial conditions for particle distribution functions are imposed in line with Eqs. (5):

$$
s_{k}(0, x)=w_{k} c_{\mathrm{s}}(0, x)=w_{k} c_{\max } \quad, \quad f_{k}(0, x)=w_{k} c_{\mathrm{f}}(0, x)=w_{k} c_{0}
$$

With regard to boundary conditions for particle distribution functions in fluid phase, let null Neumann condition at bed exit, Eq. (6), be firstly addressed. As $f_{1}(t, L)$ is obtained via streaming from the adjacent (preceding) site, first-order finite-differences discretization of $\partial c_{f} / \partial x$ together with Eq. (9) leads to (RABI; KAMIMURA, 2016):

$$
f_{2}(t, L)=f_{2}(t, L-\Delta x)
$$

At bed inlet, $f_{2}(t, 0)$ is obtained through streaming from the adjacent (subsequent) site. Dirichlet condition is imposed to $f_{1}(t, 0)$ via flux conservation (MOHAMAD, 2011):

$$
f_{1}(t, 0)=c_{\text {in }}-f_{2}(t, 0)(16)
$$

In terms of Danckwerts inlet condition, first-order finite-differences discretization of $\partial c_{f} / \partial x$ and Eq. (9) are again invoked in order to impose (RABI; KAMIMURA, 2016):

$$
f_{1}(t, 0)=\frac{f_{1}(t, 0+\Delta x)+f_{2}(t, 0+\Delta x)+\mathrm{Pe}_{\mathrm{m}} c_{\mathrm{in}}}{1+\mathrm{Pe}_{\mathrm{m}}}-f_{2}(t, 0)
$$

which reduces to Eq. (16) as $\mathrm{Pe}_{\mathrm{m}} \rightarrow \infty$ or, equivalently, as $D_{\mathrm{f}} \rightarrow 0$ (i.e. for no diffusion).

\section{RESULTS AND DISCUSSION}

Input parameters for LBM simulations were initially those in VARGAS et al. (2006) except for oil diffusivity $D_{\mathrm{f}}$ in fluid phase, which was absent in aforesaid case study as their extraction model disregarded diffusion. As stated, it is precisely such model simplification that enabled IRENE to audit eventual numerical effects in LBM simulations not only when extraction ranged from convection-dominant to diffusion-dominant but also when Dirichlet and Danckwerts boundary conditions were interchanged at bed inlet.

One may group those input parameters as temperature-independent (Table 1) or as temperature-dependent (Table 2), with the latter in view of extraction temperatures studied in VARGAS et al. (2006), namely: $40^{\circ} \mathrm{C}, 50^{\circ} \mathrm{C}, 60^{\circ} \mathrm{C}$ and $70^{\circ} \mathrm{C}$. Using parameters in Table 1, Eq. (1) renders $v=5.243 \times 10^{-4} \mathrm{~m} \mathrm{~s}^{-1}$ as interstitial fluid velocity. LBM parameters were set as $\Delta x=0.0005 \mathrm{~m}$ and $\Delta t=0.1 \mathrm{~s}$ in order to yield low lattice-based Mach number (i.e. Ma $\sim 0.1$ ) for numerical stability purposes, as suggested in MOHAMAD (2011). 
While no diffusion was modeled in VARGAS et al. (2006), essential oil diffusivity $D_{\mathrm{f}}$ in fluid phase arose as another temperature-dependent parameter, likewise intra-particle

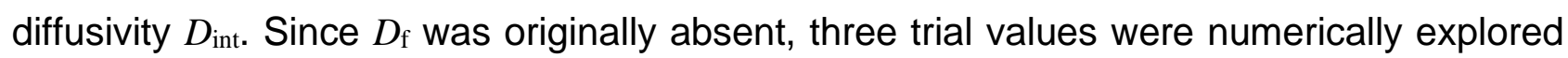
via IRENE, namely $D_{\mathrm{f}}=1.0 \times 10^{-8} \mathrm{~m}^{2} \mathrm{~s}^{-1}$ (convection-dominant extraction), $D_{\mathrm{f}}=1.0 \times 10^{-6} \mathrm{~m}^{2}$ $\mathrm{s}^{-1}$ (moderate diffusivity), and $D_{\mathrm{f}}=1.0 \times 10^{-4} \mathrm{~m}^{2} \mathrm{~s}^{-1}$ (diffusion-dominant extraction).

By imposing either Dirichlet or Danckwerts condition at inlet, LBM simulations were performed for temperatures studied in VARGAS et al. (2006) together with aforesaid trial fluid-phase diffusivities $D_{\mathrm{f}}$. It is worth citing that parameters $k_{\mathrm{p}}$ and $D_{\text {int }}$ were fine-tuned in VARGAS et al. (2006) against a convection-only model. Hence, $k_{\mathrm{p}}-D_{\text {int }}$ duets in Table 2 (as initially adopted in LBM simulations) could be disputable in a convection-diffusion model such as IRENE. In what follows, major attention is devoted to potential numerical effects in LBM simulations, but results accuracy is equally addressed and discussed.

\subsection{ESSENTIAL OIL CONCENTRATION IN GORSE PARTICLES AT BED INLET}

For extraction temperatures in VARGAS et al. (2006), Figure 1 shows simulations of time evolution of essential oil concentration $c_{\mathrm{s}, \text { in }}(t)=c_{\mathrm{s}}(t, 0)$ in solid phase at bed inlet. While monitoring those time-dependent concentration profiles may help infer upon bed depletion kinetics, the literature usually lacks experimental counterparts for comparison purposes. 
Figure 1 - Imposing either Dirichlet or Danckwerts inlet condition: influence on time evolution of essential oil concentration in solid phase at bed inlet for extraction at (a) $40^{\circ} \mathrm{C}$, (b) $50^{\circ} \mathrm{C}$, (c) $60^{\circ} \mathrm{C}$, and (d) $70^{\circ} \mathrm{C}$.

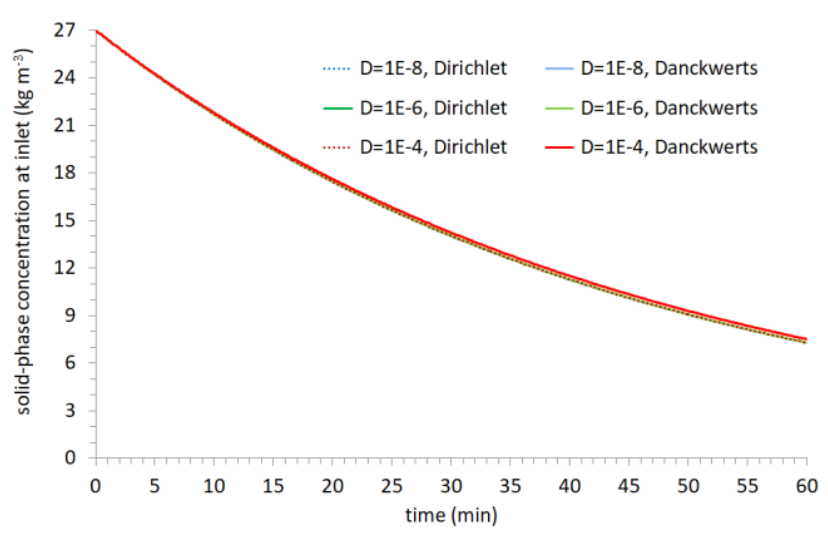

(a)

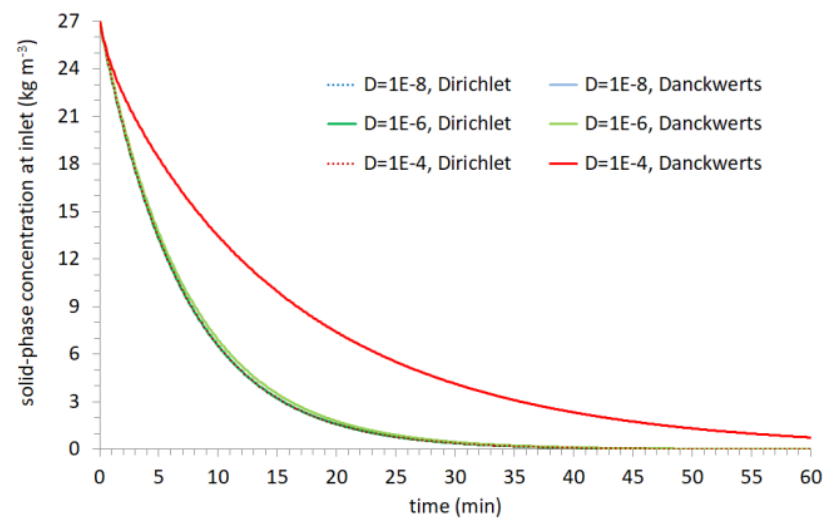

(c)

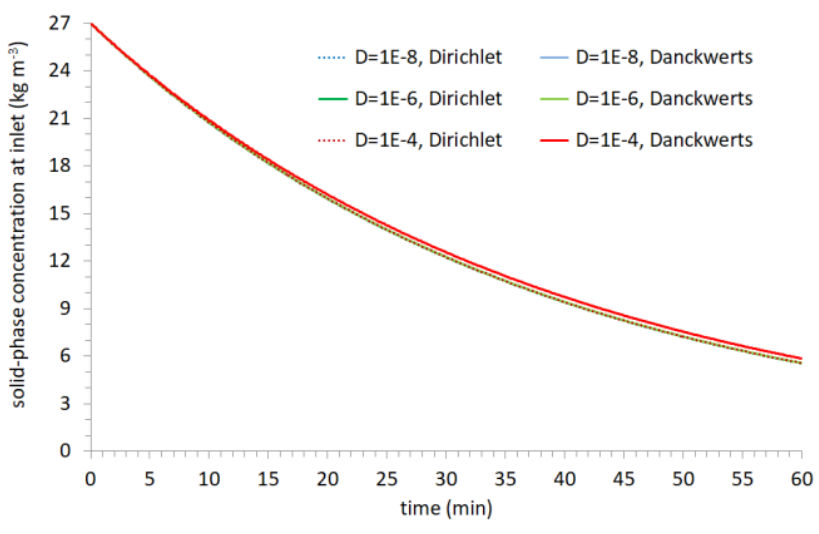

(b)

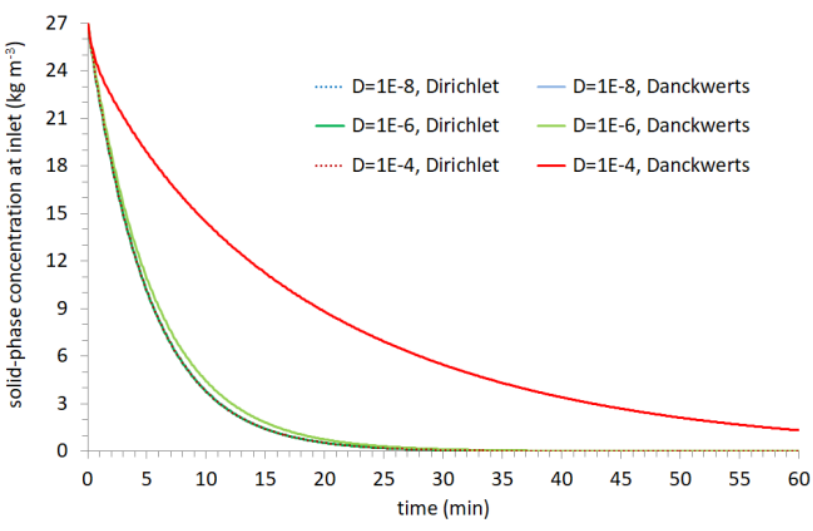

(d)

Source: own authorship.

Gorse particles at bed inlet $(z=0)$ are closer to incoming (thus relatively cleaner) solvent. Hence, they are exposed to larger concentration gradients, thus leading to higher transfer rates of essential oil from gorse particles to incoming supercritical fluid.

In terms of numerical effects in LBM simulations of particles depletion at bed inlet, the following remarks arise:

- With input data for extractions at $40^{\circ} \mathrm{C}$ and $50^{\circ} \mathrm{C}$, simulations were basically the same regardless of fluid-phase diffusivity $D_{\mathrm{f}}$ and Dirichlet-Danckwerts inlet conditions. As local depletion (oil transfer rates from particles) were insensitive to extraction scenarios (i.e. convection or diffusion-dominant) as well as inlet condition type, fine-tuned $k_{\mathrm{p}}-D_{\text {int }}$ duets in Table 2 for $40^{\circ} \mathrm{C}$ and $50^{\circ} \mathrm{C}$ might be misleading in convection-diffusion models.

- For extractions at $60^{\circ} \mathrm{C}$ and $70^{\circ} \mathrm{C}$, relatively larger concentration profiles were simulated with $D_{\mathrm{f}}=1.0 \times 10^{-4} \mathrm{~m}^{2 \mathrm{~s}-1}$ (diffusion-dominant extraction) and Danckwerts inlet condition. This is feasible because Danckwerts condition allows back diffusion at bed inlet so that 
incoming solvent becomes less 'clean' as $D_{\mathrm{f}}$ augments, which decreases concentration gradients between solid and fluid phases, thus reducing transfer rates. On the contrary, there was no significant effect when Dirichlet condition was imposed at bed inlet.

- Final (i.e. at $t=60 \mathrm{~min}$ ) solid-phase concentrations at inlet were quite lower (i.e. almost local depletion) mainly for convection-dominant extractions at $60^{\circ} \mathrm{C}$ and $70^{\circ} \mathrm{C}$. This is expected as $k_{\mathrm{p}}-D_{\text {int }}$ duets in Table 2 were fine-tuned in a convection-only model.

\subsection{ESSENTIAL OIL CONCENTRATION IN SUPERCRITICAL FLUID AT BED EXIT}

The sequence in Figure 2 shows LBM simulations of the time evolution of essential oil concentration $c_{\mathrm{f} \text {,out }}(t)=c_{\mathrm{f}}(t, L)$ in fluid phase at bed exit. Although experimental data are indeed collected at bed exit, they do not refer to oil concentration itself but rather to time evolution of mass-basis extraction yield, also referred to as extraction kinetics (SOVOVÁ, 1994; REVERCHON, 1996; RAl et al., 2014; DE OLIVEIRA et al., 2018).

As general observation from LBM simulations, relatively large amounts of essential oil are extracted (i.e. leave the extractor) during early instants, evidenced by sudden rise in fluid-phase concentration. As extraction continues, gorse particles become more and more depleted over the bed and, hence, fluid-phase concentration gradually decreases at bed exit. In terms of numerical effects in LBM simulations while in consideration of results in section 4.1, the following remarks arise:

- As gorse particles depletion was lower (i.e. particles retained more oil) for extractions simulated at $40^{\circ} \mathrm{C}$ and $50^{\circ} \mathrm{C}$ in Figure $1(\mathrm{a})$-(b), oil concentrations in fluid phase at bed exit were relatively lower for those scenarios as evidenced in Figure 2(a)-(b).

- For either $D_{\mathrm{f}}=1.0 \times 10^{-8} \mathrm{~m}^{2} \mathrm{~s}^{-1}$ (convection-dominant extraction) or $D_{\mathrm{f}}=1.0 \times 10^{-6} \mathrm{~m}^{2} \mathrm{~s}^{-1}$ (moderate diffusivity) only minor effects (if any) were noted as Dirichlet or Danckwerts boundary conditions were interchanged at bed inlet. This is mathematically expected as Eq. (8) simplifies to Eq. (7) for $D_{\mathrm{f}} \rightarrow 0$.

- For extractions simulated with $D_{\mathrm{f}}=1.0 \times 10^{-8} \mathrm{~m}^{2} \mathrm{~s}^{-1}$ (convection-dominant extraction), very sharp concentration peaks occurred at initial instants, which mathematically refer to relatively high (and probably unrealistic) derivatives with respect to time.

- Differences became evident for $D_{\mathrm{f}}=1.0 \times 10^{-4} \mathrm{~m}^{2} \mathrm{~s}^{-1}$ (diffusion-dominant extraction) as simulations under Dirichlet condition were noticeably undervalued whereas those under Danckwerts condition were closer to counterparts using relatively higher $D_{\mathrm{f}}$. This might 
suggest that Danckwerts inlet condition could be more realistic in convection-diffusion models and should be preferred.

- For LBM simulations with $D_{\mathrm{f}}=1.0 \times 10^{-4} \mathrm{~m}^{2} \mathrm{~s}^{-1}$ (diffusion-dominant extraction) and under Danckwerts inlet condition, back-diffusion at inlet combined with extracted oil hold-up over the bed might explain relatively higher oil concentrations in fluid phase at exit.

Figure 2 - Imposing either Dirichlet or Danckwerts inlet condition: influence on time evolution of essential oil concentration in in fluid phase at bed exit for extraction at (a) $40^{\circ} \mathrm{C}$, (b) $50^{\circ} \mathrm{C}$, (c) $60^{\circ} \mathrm{C}$, and (d) $70^{\circ} \mathrm{C}$.

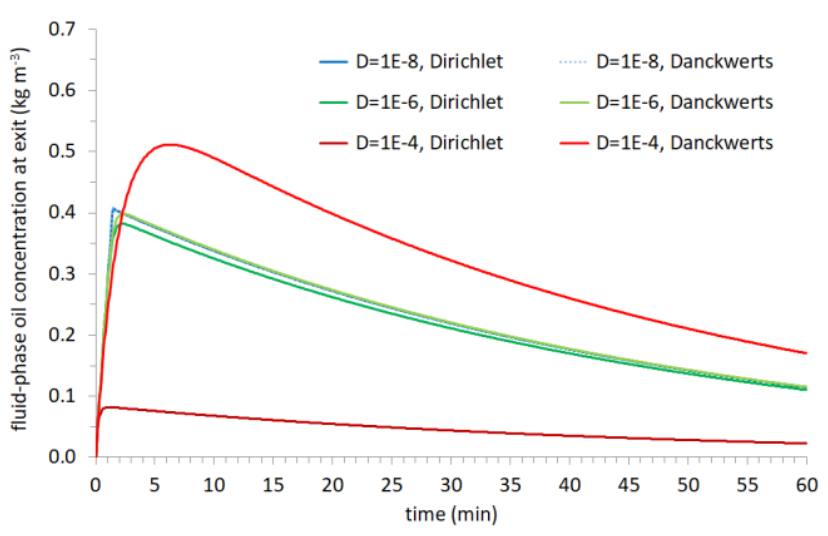

(a)

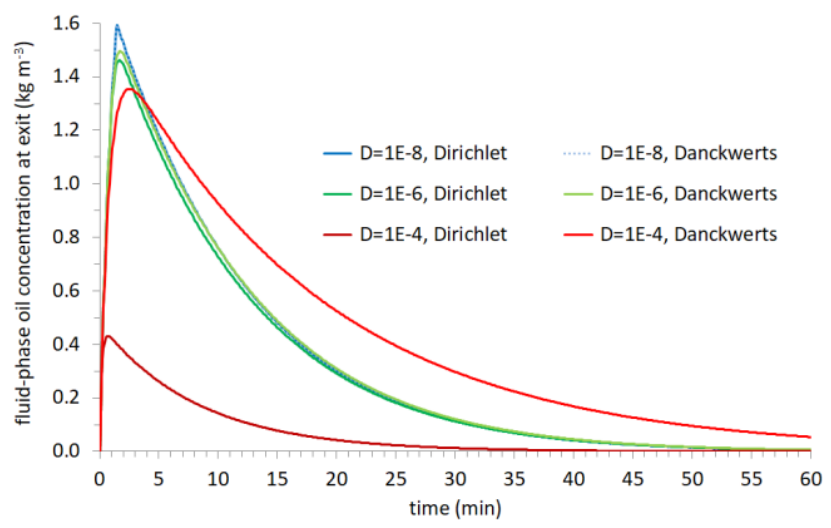

(c)

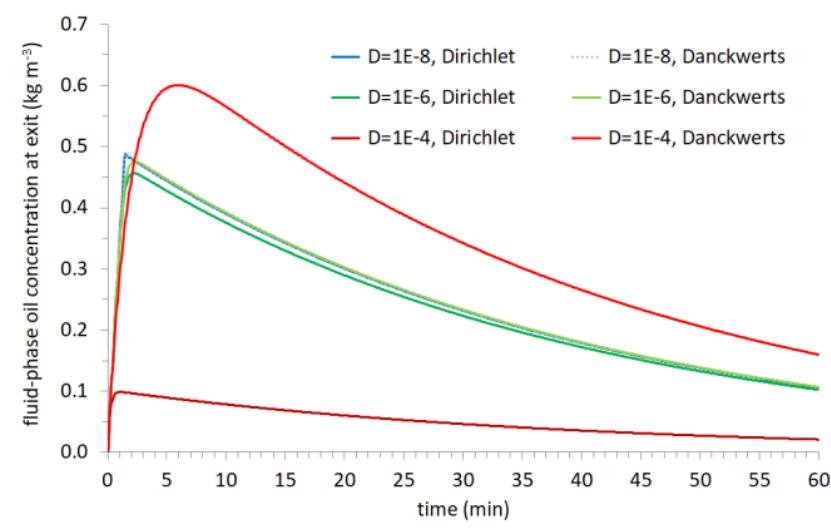

(b)

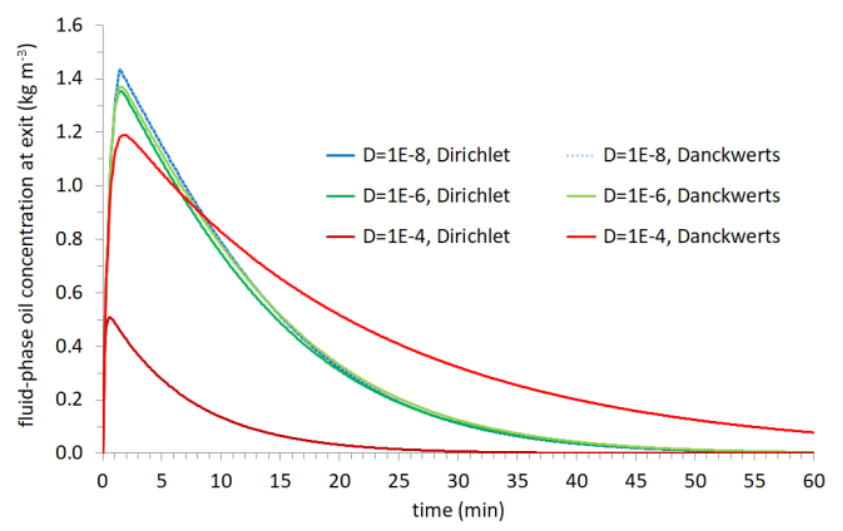

(d)

Source: own authorship.

\subsection{MASS-BASIS EXTRACTION YIELD (EXTRACTION KINETICS)}

Aiming at depicting any species behavior over the bed during extraction, IRENE is able to provide species concentrations in either solid or fluid phases at any time $t$ and axial position $x$ whatsoever. Nonetheless (and perhaps regrettably), those numerically simulated results seldom have experimental counterparts as data in the literature are often available 
as mass-basis extraction yields (extraction kinetics), whose raw data are collected at bed exit (SOVOVÁ, 1994; REVERCHON, 1996; RAl et al., 2014; DE OLIVEIRA et al., 2018).

In view of that, IRENE numerically retrieves time-dependent behavior of mass-basis extraction yield for comparison purposes with extant experimental data. Based on the total mass $m_{\text {total }}$ of solid particles in the bed, dynamic extraction kinetics profile $Y(t)$ is assessed from fluid-phase concentration $c_{\mathrm{f}, \mathrm{out}}(t)=c_{\mathrm{f}}(t, L)$ simulated at bed exit $(x=L)$ as follows:

$$
Y(t)=\frac{1}{m_{\text {total }}} \int_{0}^{t} \dot{V} c_{\mathrm{f}, \text { out }}\left(t^{\prime}\right) \mathrm{d} t^{\prime} \quad \stackrel{\dot{V}=\text { constant }}{\longrightarrow} \quad Y(t)=\frac{\dot{V}}{m_{\text {total }}} \int_{0}^{t} c_{\mathrm{f}}\left(L, t^{\prime}\right) \mathrm{d} t^{\prime}
$$

IRENE numerically evaluates the integral in Eq. (18).

The sequence in Figure 3 compares the time evolution of extraction kinetics from LBM simulations, which can now be compared with experimental data from VARGAS et al. (2006). It is worth noting that IRENE numerically simulates extraction kinetics curves from phenomenological reasoning (i.e. physics-based modeling) rather than heuristically bestfitting 'a priori' dictated piecewise mathematical functions against experimental data.

Figure 3 - Imposing either Dirichlet or Danckwerts inlet condition: influence on time evolution of mass-basis extraction yield (kinetics) for extraction at (a)

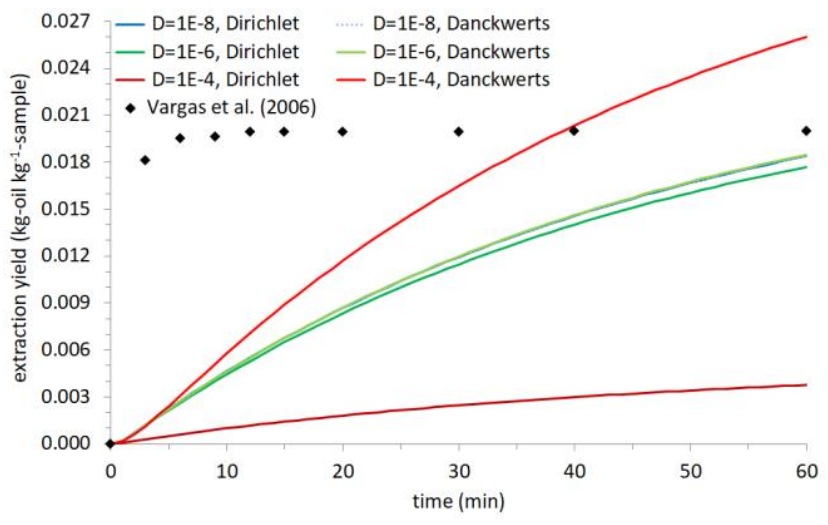

(a)

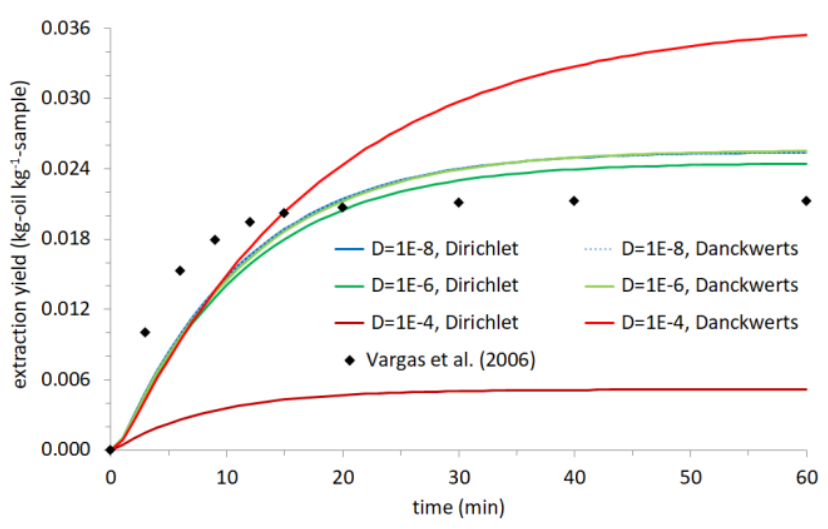

(c)

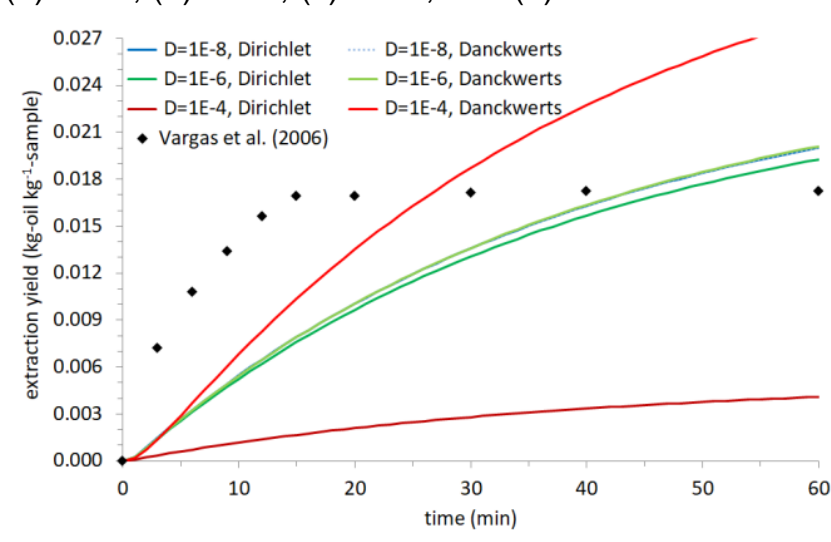

(b)

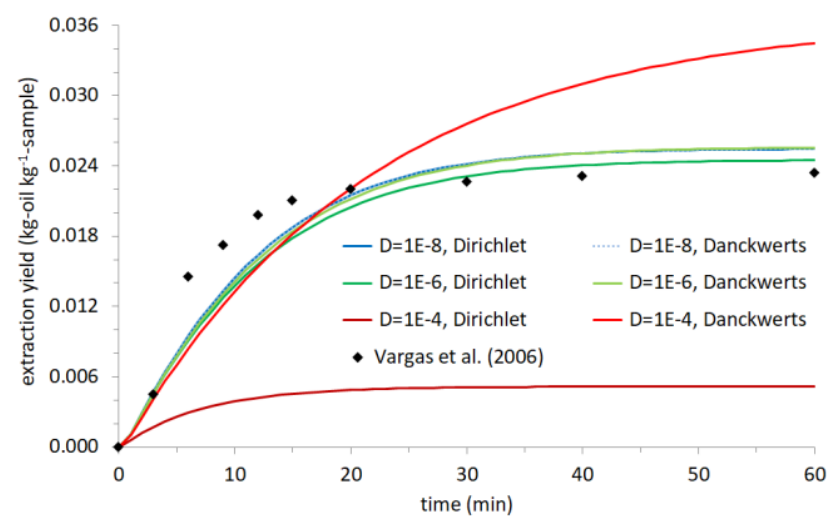

(d) 
Source: own authorship.

In terms of numerical effects in simulations while considering results from previous sections (especially from section 4.2, which IRENE used in Eq. (18) to numerically retrieve extraction kinetics dynamic profile), the following remarks arise:

- Fine-tuned $k_{\mathrm{p}}-D_{\text {int }}$ duets in Table 2 for extractions at $40^{\circ} \mathrm{C}$ and $50^{\circ} \mathrm{C}$ led to dissimilar extraction kinetics as simulated using more comprehensive models, regardless of fluidphase diffusivity $D_{\mathrm{f}}$ and inlet condition type. As shown in Figure 2 for simulations with $D_{\mathrm{f}}$ $=1.0 \times 10^{-4} \mathrm{~m}^{2} \mathrm{~s}^{-1}$, when Dirichlet and Danckwerts inlet conditions were interchanged, huge differences arose in fluid-phase concentrations $c_{\mathrm{f}}$, which mathematically rendered distinct extraction yields, thus reinforcing that $k_{\mathrm{p}}-D_{\text {int }}$ in Table 2 might not be suitable to numerically simulate extractions in diffusion-dominant scenarios.

- For $D_{\mathrm{f}}=1.0 \times 10^{-4} \mathrm{~m}^{2} \mathrm{~s}^{-1}$ (diffusion-dominant extraction), LBM simulations under Dirichlet inlet condition underestimated extraction kinetics whereas those under Danckwerts inlet condition started to become considerably higher than counterparts when bed depletion instants (i.e. asymptotic extraction yields) were experimentally reached.

- For simulations with $D_{\mathrm{f}}=1.0 \times 10^{-6} \mathrm{~m}^{2} \mathrm{~s}^{-1}$ (moderate diffusivity) and $D_{\mathrm{f}}=1.0 \times 10^{-8} \mathrm{~m}^{2} \mathrm{~s}^{-1}$ (convection-dominant extraction), interchanging Dirichlet and Danckwerts conditions at bed inlet brought about minor differences, which is expected as Eq. (8) mathematically simplifies to Eq. (7) inasmuch as $D_{\mathrm{f}} \rightarrow 0$.

\subsection{FINE-TUNING EXTRACTION PARAMETERS USING COMPREHENSIVE MODELS}

As pointed in SAM SAGUY (2016), virtualization is vital for agroindustrial RD\&I and comprehensive computational modeling become a versatile engineering tool (DE SOUZASANTOS, 2010). The present work numerically simulated biocompounds extraction based on convection-diffusion model and imposing either Dirichlet or Danckwerts inlet condition. While IRENE reasonably simulated typical trend of extraction kinetics using input data for extractions at $60^{\circ} \mathrm{C}$ and $70^{\circ} \mathrm{C}$, numerical effects jeopardized extractions simulated at $40^{\circ} \mathrm{C}$ and $50^{\circ} \mathrm{C}$, with rising parts of extraction kinetics largely deviating from experimental data.

Those deviations are prone to result from the fact that $k_{\mathrm{p}}-D_{\text {int }}$ input duets in Table 2 were formerly fine-tuned in VARGAS et al. (2006) by fully disregarding diffusive transport in Eq. (4). In other words, original $k_{\mathrm{p}}-D_{\text {int }}$ values (used to simulate extractions at $40^{\circ} \mathrm{C}$ and $50^{\circ} \mathrm{C}$ ) 
could be 'convection-biased' and, hence, arguable in convective-diffusive extraction models (e.g. as numerically implemented in IRENE).

One could then enquiry about alternative $k_{\mathrm{p}}-D_{\text {int }}$ duets as input values for IRENE. Accordingly, trial LBM simulations were further performed bearing in mind the extraction at $40^{\circ} \mathrm{C}$ by relaxing $k_{\mathrm{p}}$ and $D_{\text {int }}$ from their original values in Table 2 while still interchanging Dirichlet and Danckwerts boundary conditions at bed inlet.

For simulations in Figure 4, partition coefficient was kept at $k_{\mathrm{p}}=0.08$ while three values intra-particle diffusivity were tested: $D_{\text {int }}=1.0 \times 10^{-10} \mathrm{~m}^{2} \mathrm{~s}^{-1}, D_{\text {int }}=2.0 \times 10^{-10} \mathrm{~m}^{2} \mathrm{~s}^{-1}$ and $D_{\text {int }}=$ $3.0 \times 10^{-10} \mathrm{~m}^{2} \mathrm{~s}^{-1}$. For simulations in Figure 5, intra-particle diffusivity was kept at $D_{\text {int }}=1.0 \times$ $10^{-10} \mathrm{~m}^{2} \mathrm{~s}^{-1}$ while three partition coefficients were tested: $k_{\mathrm{p}}=0.08, k_{\mathrm{p}}=0.12$ and $k_{\mathrm{p}}=0.16$. Figure 4 and Figure 5 show the time evolution of (a) essential oil concentration $c_{\text {f,out }}(t)$ in fluid phase at bed exit and (b) mass-basis extraction yield $Y(t)$, respectively. 
Figure 4 - Numerical simulations of extraction at $40^{\circ} \mathrm{C}$ by relaxing intra-particle diffusivity from original values: time evolution of (a) fluid-phase essential oil concentration at bed exit and (b) mass-basis extraction yield.

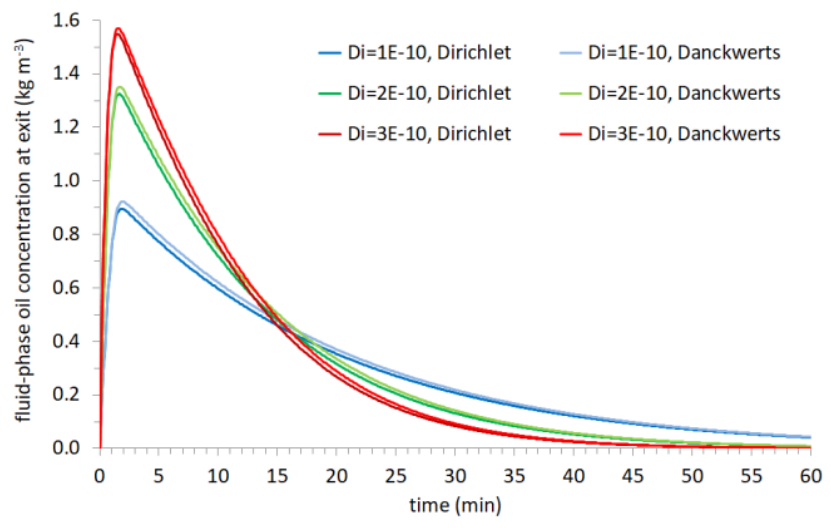

(a)

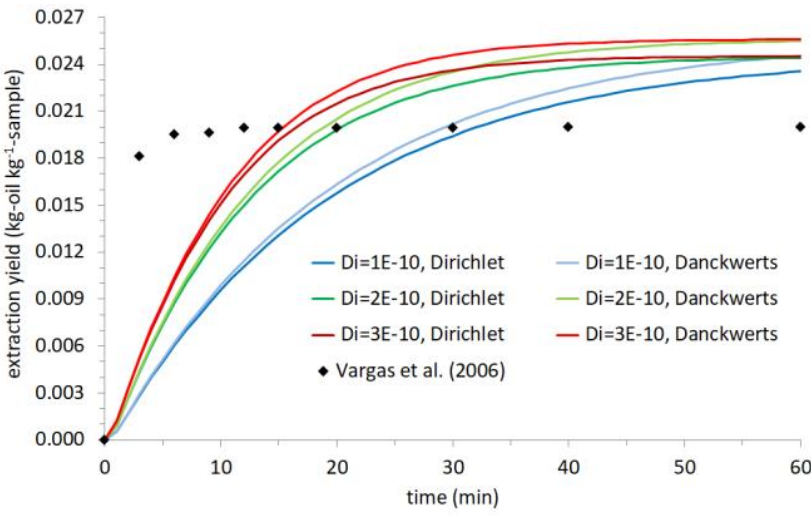

(b)

Source: own authorship.

Figure 5 - Numerical simulations of extraction at $40^{\circ} \mathrm{C}$ by relaxing partition coefficient from original values: time evolution of (a) fluid-phase essential oil concentration at bed exit and (b) mass-basis extraction yield.

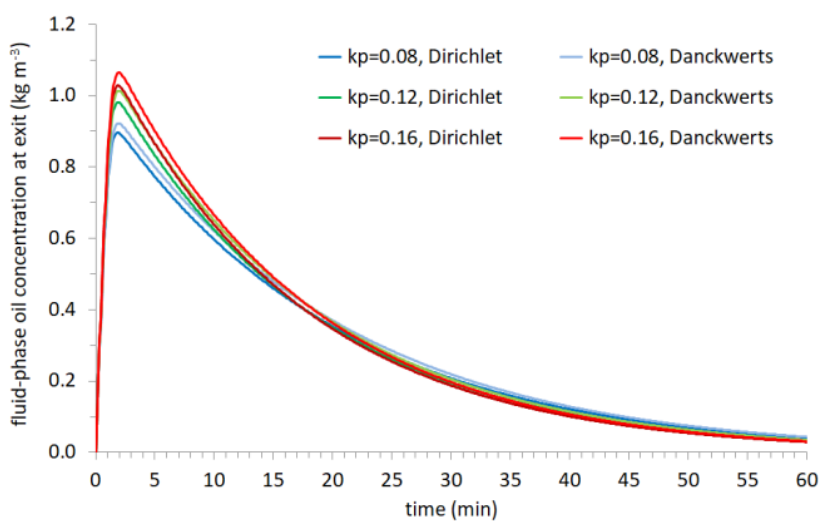

(a)

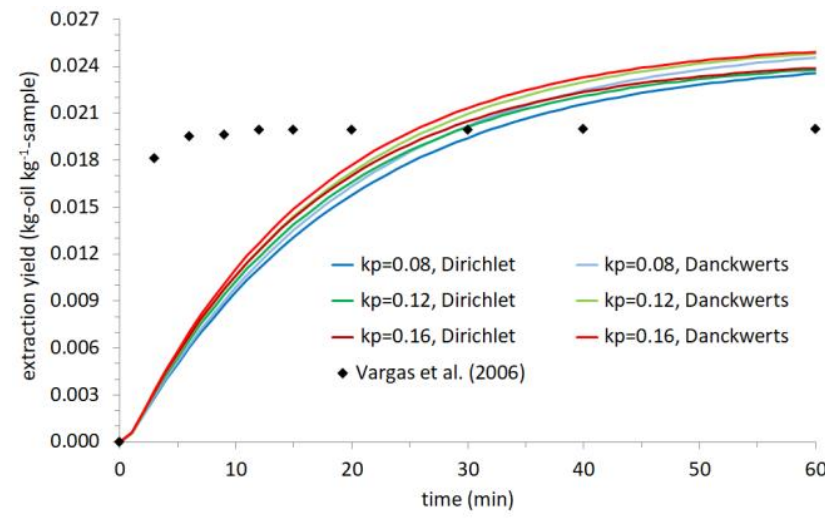

(b)

Source: own authorship.

Those preliminary LBM simulations in Figure 4 and Figure 5 should be compared with counterparts in Figure 2(a) and Figure 3(a), respectively. One notes that relaxing both $k_{\mathrm{p}}$ and $D_{\text {int }}$ from their original (i.e. 'convection-biased') values tends to improve the related numerical results. As far as fluid-phase diffusivity is concerned, Figure 3 suggests that $D_{\mathrm{f}}$ seems to dictate (i.e. are linked to) asymptotic values of mass-basis extraction yields.

Virtualization of continuous-flow biocompounds extraction should then employ input parameters fine-tuned against relatively more comprehensive models invoking diffusion in addition to convection, as the former mass transport mechanism can be influential in large equipment (REIS-VASCO et al., 2000; GASPAR et al., 2003; ROSA et al., 2016; PONTES 
et al., 2017). While governing differential equations remain parabolic in pure-convection models, they become elliptic if species diffusion is further considered.

By entailing $k_{\mathrm{p}}$ and $D_{\text {int }}$ together with $D_{\mathrm{f}}$ and/or other process parameters (e.g. $c_{\max }$ ), such a task can be rationalized with the help of dimensionless models (RABI et al., 2020). Nevertheless, a systematic study on best-fitting extraction model parameters is beyond the scope of the present work.

\section{CONCLUSION}

Physics-based models of biocompounds extraction tend to be complex enough so that numerical methods become necessary, which invoke input parameters taken from the literature. By relying on an extant convention-diffusion model for continuous-flow extraction of essential oil from gorse, this work examined potential effects on numerical simulations performed with input parameters fine-tuned against a pure-convection model. Also, either Dirichlet or Danckwerts condition was imposed to fluid-phase concentration at bed inlet.

While the expected trend of extraction yield curves was reasonably simulated, input parameters fine-tuned against pure-convection model resulted unsuitable for simulations based on convection-diffusion model. Numerical results also suggested that Danckwerts boundary condition should be preferred at bed inlet as Dirichlet condition underestimated species (i.e. oil) concentrations simulated in the fluid phase.

Systematic fine-tuning of input parameters proved to be still required, particularly in view of relatively comprehensive extraction models, e.g. additionally considering mass (i.e. species) diffusion in conjunction with convection. By invoking an allegedly Einstein's quote, "everything should be made as simple as possible, but no simpler".

\section{REFERENCES}

ALBER, M.; BUGANZA TEPOLE, A.; CANNON, W. R. et al. Integrating machine learning and multiscale modeling - perspectives, challenges, and opportunities in the biological, biomedical, and behavioral sciences. npj Digital Medicine, v. 2: 115, 2019.

BERTOLDI, L. T. M.; RIBEIRO, R.; DACANAL, G. C.; CANEPPELE, F. L.; RABI, J. A. Influence of inner structure, porosity and degradation kinetics on pectin extraction from fruit peels in agitated-batch extractor: Computational modelling via lattice Boltzmann method. Food Structure, v. 29: 100209, 2021. 
CALVET, S.; GATES, R. S.; ZHANG, G. Q.; ESTELLÉS, F., OGINK, N. W. M.;

PEDERSEN, S.; BERCKMANS, D. Measuring gas emissions from livestock buildings: A review on uncertainty analysis and error sources. Biosystems Engineering, v. 116(3): 221-231, 2013.

DANCKWERTS, P. V. Continuous flow systems. Distribution of residence times. Chemical Engineering Science, v. 2: 1-13, 1953.

DE OLIVEIRA, N. A.; CORNELIO-SANTIAGO, H. P., FUKUMASU, H., DE OLIVEIRA, A. L. Green coffee extracts rich in diterpenes - Process optimization of pressurized liquid extraction using ethanol as solvent. Journal of Food Engineering, v. 224: 148-155, 2018.

DE SOUZA-SANTOS, M. L. Solid Fuels Combustion and Gasification: Modeling, Simulation, and Equipment Operations, 2nd ed. CRC Press, Boca Raton, 2010.

DIAZ, M. S.; BRIGNOLE, E. A. Modeling and optimization of supercritical fluid processes. The Journal of Supercritical Fluids, v. 47: 611-618, 2009.

DURÁN, R.; VILLA, A. L.; RIBEIRO, R.; RABI, J. A. Pectin extraction from mango peels in batch reactor: dynamic one-dimensional modeling and lattice Boltzmann simulation.

Chemical Product and Process Modeling, v. 10: 203-210, 2015.

FORTUNATO, V. A.; CANEPPELE, F. L.; RIBEIRO, R.; RABI, J. A. Development of inhouse lattice-Boltzmann simulator of bioreactors for wastewater treatment: basic concepts and initial results. Water Science and Technology, v. 77(3): 838-847, 2018.

GASPAR, F.; LU, T.; SANTOS, R.; AL-DURI, B. Modelling the extraction of essential oils with compressed carbon dioxide. The Journal Supercritical Fluids, v. 25: 247-260, 2003.

GHOULEM, M.; EL MOUEDDEB, K.; NEHDI, E.; BOUKHANOUF, R.; CALAUTIT, J. K. Greenhouse design and cooling technologies for sustainable food cultivation in hot climates: Review of current practice and future status. Biosystems Engineering, v. 183: 121-150, 2019.

HORABIK, J.; MOLENDA, M. Parameters and contact models for DEM simulations of agricultural granular materials: A review. Biosystems Engineering, v. 147, 206-225, 2016.

LI, Y.; DING, Y.; LI, D.; MIAO, Z. Automatic carbon dioxide enrichment strategies in the greenhouse: A review. Biosystems Engineering, v. 171: 101-119, 2018.

MCNAMARA, G. R.; ZANETTI, G. Use of the Boltzmann equation to simulate lattice-gas automata. Physical Review Letters, v. 61: 2332-2335, 1998.

MOHAMAD, A. A. Lattice Boltzmann Method: Fundamentals and Engineering Applications with Computer Codes. Springer-Verlag, London, 2011. 
OKIYAMA, D. C. G.; KAMIMURA, E. S.; RABI, J. A. Biospecific affinity chromatography: computational modelling via lattice Boltzmann method and influence of lattice-based dimensionless parameters. International Journal of Biotechnology for Wellness Industries, v. 4: 40-50, 2015.

OKIYAMA, D. C. G.; RABI, J. A. Lattice-Boltzmann simulation of transport phenomena in agroindustrial biosystems. In: KORA, A. B. (Ed.), Advances in Computational Modeling Research: Theory, Developments and Applications, pp. 79-104. Nova Science Publishers, Hauppauge, 2013.

PONTES, P. C.; NAVEIRA-COTTA, C. P.; QUARESMA, J. N. N. Three-dimensional reaction-convection-diffusion analysis with temperature influence for biodiesel synthesis in micro-reactors. International Journal of Thermal Sciences, v. 118: 104-122, 2017.

RABI, J. A.; CANEPPELE, F. L.; RIBEIRO, R.; DACANAL, G. C. Scale-up of extraction processes: Dimensionless modeling and virtualization via lattice Boltzmann method. Journal of Food Process Engineering, v. 43(1): e13244, 2020.

RABI, J. A.; KAMIMURA, E. S. Lattice-Boltzmann simulation of lipase separation via bioaffinity chromatography: imposing Dirichlet or Danckwerts inlet condition. Procedia Engineering, v. 157: 238-245, 2016.

RAI, A.; PUNASE, K. D.; MOHANTY, B.; BHARGAVA, R. Evaluation of models for supercritical fluid extraction. International Journal of Heat and Mass Transfer, v. 72: 274-287, 2014.

REIS-VASCO, E. M. C.; COELHO, J. A. P.; PALAVRA, A. M. F.; MARRONE, C.; REVERCHON, E. Mathematical modelling and simulation of pennyroyal essential oil supercritical extraction. Chemical Engineering Science, v. 55: 2917-2922, 2000.

REVERCHON, E. Mathematical modeling of supercritical extraction of sage oil. AIChE Journal, v. 42: 1765-1771, 1996.

ROSA, R. H., VON ATZINGEN, G. V., BELANDRIA, V., DE OLIVEIRA, A. L., BOSTYN, S., RABI, J. A. Lattice Boltzmann simulation of cafestol and kahweol extraction from green coffee beans in high-pressure system. Journal of Food Engineering, v. 176: 88-96, 2016.

SAM SAGUY, I. Challenges and opportunities in food engineering: Modeling, virtualization, open innovation and social responsibility. Journal of Food Engineering, v. 176: 2-8, 2016.

SOVOVÁ, H. Rate of the vegetable oil extraction with supercritical $\mathrm{CO} 2-\mathrm{I}$. Modeling of extraction curves. Chemical Engineering Science, v. 49: 409-414, 1994.

SUCCI, S. The Lattice Boltzmann Equation for Fluid Dynamics and Beyond. Oxford University Press, Oxford, 2001.

TANNY, J. Microclimate and evapotranspiration of crops covered by agricultural screens: A review. Biosystems Engineering, v. 114(1): 26-43, 2013. 
VAN DER SMAN, R. G. M. Lattice Boltzmann simulation of microstructures. In: SABLANI, S. S.; RAHMAN, M. S.; DATTA, A. K.; MUJUMDAR, A. R. (Eds.), Handbook of Food and Bioprocess Modeling Techniques, pp. 15-39. CRC Press, Boca Raton, 2007.

VARGAS, R. M. F.; CASSEL, E.; GOMES, G. M. F.; LONGHI, L. G. S.; ATTI-SERAFINI, L., ATTI-SANTOS, A. C. Supercritical extraction of carqueja essential oil: experiments and modeling. Brazilian Journal of Chemical Engineering, v. 23: 375-382, 2006.

\section{ACRONYMS}

IRENE In-house Reification Environment for Numerical Experimentation

LBE Lattice Boltzmann Equation

LBM Lattice Boltzmann Method

RD\&I Research, Development and Innovation 


\section{RESUMO}

Modelos fenomenológicos são essenciais à engenharia de bioprocessos e naqueles para extração de biocompostos em fluxo contínuo, a difusão requer condição de contorno extra na saída (geralmente condição de Neumann nula) enquanto que a condição de Dirichlet ou Danckwerts pode ser imposta na entrada. Usando um estudo de caso e um simulador próprio via método de Boltzmann em rede, este trabalho numericamente examina efeitos ao trocar as condições de entrada supracitadas. Simulações consideram cenários com predomínio convectivo ao difusivo e rendimentos de extração sob cada condição de entrada foram comparados com dados experimentais. Curvas de rendimento foram satisfatoriamente reproduzidas em simulações numéricas usando parâmetros adequados e diferenças devido a mudanças de condições na entrada tornaram-se evidentes apenas em cenários de extração com predomínio de transporte difusivo. Para difusividades da ordem $10^{-6} \mathrm{~m}^{2} \mathrm{~s}^{-1}$, resultados numéricos apontam para impor a condição de contorno de Danckwerts junto à entrada do leito.

Palavras-chave: Bioprodutos. Bioprocessos. Modelagem matemática. Simulação numérica. Método de Boltzmann em rede.

\section{RESUMEN}

Los modelos fenomenológicos son esenciales para la ingeniería de bioprocesos y en aquellos para la extracción de biocompuestos en flujo continuo, la difusión requiere una condición de frontera en la salida (generalmente condición de Neumann nula) mientras que la condición de Dirichlet o Danckwerts se puede imponer en la entrada. Utilizando un estudio de caso y un simulador por el método de Boltzmann en red, este trabajo examina los efectos al cambiar las condiciones de entrada citadas. Las simulaciones consideran escenarios con predominio convectivo a difusivo y los rendimientos de extracción bajo cada condición de entrada se compararon con datos experimentales. Las curvas de rendimiento se reprodujeron en las simulaciones con parámetros adecuados y las diferencias al cambiar las condiciones de entrada se hicieron evidentes solo para la extracción con predominio difusivo. Para difusividad $\sim 10^{-6} \mathrm{~m}^{2} \mathrm{~s}^{-1}$, los resultados apuntan a imponer la condición de Danckwerts en la entrada del lecho.

Palabras-clave: Bioproductos. Bioprocesos. Modelo matematico. Simulación numérica. Método de Boltzmann en red. 


\section{LICENÇA DE USO}

Este é um artigo publicado em acesso aberto (Open Access) sob a licença Creative Commons Atribuição 4.0 Internacional (CC BY 4.0), que permite uso, distribuição e reprodução em qualquer meio, desde que o trabalho original seja corretamente citado. Mais informações em: http://creativecommons.org/licenses/by/4.0

\section{CONFLITO DE INTERESSES}

Os autores declaram que não há conflito de interesses neste trabalho.

\section{CONTRIBUIÇÕES AUTORAIS}

Autor 1: Levantamento, análise e interpretação dos dados; redação.

Autor 2: Modelagem \& simulação; análise e interpretação dos dados; redação.

\section{FINANCIAMENTO}

O presente trabalho não contou com apoio financeiro.

\section{COMO REFERENCIAR}

OLIVEIRA, Naila Albertina de; RABI, José Antonio. Continuous-flow extraction of biocompounds in fixed bed: influence of swapping from dirichlet to danckwerts condition at inlet in phenomenological models. Revista Brasileira de Engenharia de Biossistemas (Tupã), v. 15, n. 4, p. 538-560, 2021. DOI:

http://dx.doi.org/10.18011/bioeng2021v15n4p538-560.

\section{RESPONSABILIBADE EDITORIAL}

Prof. Dr. Fernando Ferrari Putti ${ }^{1}$, Prof. Dr. Paulo Sérgio Barbosa dos Santos ${ }^{1}$, Prof. Dr. Eduardo Festozo Vicente ${ }^{1}$ e Prof. Dr. Diogo de Lucca Sartori ${ }^{1}$

1 Universidade Estadual Paulista "Júlio de Mesquita Filho", FCE - Faculdade de Ciências e Engenharia, Tupã, SP, Brasil. 